MONOGRÁFICO

\title{
REDES TERRITORIALES DE ACCIÓN SOCIOEDUCATIVA. UNA APUESTA POR LA INNOVACIÓN SOCIAL COLABORATIVA
}





\section{PRESENTACIÓN}

En la última década se ha reconocido y se promueve la educación a lo largo de toda la vida, proponiéndose su extensión tanto en amplitud y profundidad -educación integral que alcanza todas las dimensiones del ser humano- como en su continuidad en las diferentes etapas del ciclo vital de las personas. En parte es el resultado de los efectos de la globalización, la hiperconectividad, los cambios acelerados en el conocimiento y en los sistemas de producción, y también de una mayor asunción del estatus de ciudadanía y el derecho al ocio y la cultura. Esta revalorización ha llevado al pensamiento pedagógico a discutir la validez de las clásicas definiciones de educación formal, no formal e informal ante la necesidad de abordar los desafíos educativos actuales de un modo más global e interdependiente (Caride, 2004; Ortega, 2005; Fullan, 2013), en donde todas las pedagogías son de primera y se entrelaza lo social y educativo (Civís \& Riera, 2007), lo escolar y no escolar (March \& Orte, 2014), para potenciar y enriquecer conjuntamente el proyecto de construir una mejor humanidad.

En la sociedad red (Castells, 2000) la escuela pierde el monopolio de la instrucción y se ve abocada a responder a necesidades socioeducativas de la infancia que en otra época correspondían casi exclusivamente a la familia y a la educación social. La creciente complejidad lleva la crisis a los Sistemas Educativos y, con ella, retorna a la sociedad el eterno debate sobre quién debe educar, qué debe educarse y cómo hay que educar. Debate que alcanza la esencia misma de las políticas públicas en educación, mayoritariamente centradas en lo escolar y que, tal como venimos reflexionando desde hace algunos años, abre una interesante oportunidad ya que, a nuestro entender, más que un inconveniente supone situar a la escuela en una perspectiva conceptual de la educación más amplia y social que la generada desde la perspectiva de la simple instrucción de los jóvenes. Con ello, la escuela y los docentes comparten espacio profesional con otros agentes educativos que operan en el territorio, pero que no dependen de la disciplina escolar (Longás, 2008: 264).

En ningún caso la supuesta crisis de la escuela significa la crisis de la educación, puesto que su papel es primordial para responder a las necesidades de desarrollo humano y, a la vez, a las crecientes situaciones de fractura social y exclusión. Dicha crisis más bien invoca a traspasar los límites de la educación restringida al currículum para encontrar formas de educar más colectivas e integradas que pongan la comunidad en el centro de los intereses. En este sentido, disponemos de suficientes evidencias de cómo la búsqueda de respuesta educativa a las actuales desafíos sociales está generando nuevas formas de acción socioeducativa que comporta la transformación de los roles educativos de docentes, educadores sociales y el conjunto de actores que de forma directa o indirecta desempeña funciones educativas. Pueden apreciarse dichos cambios en experiencias de nivel micro, generadas por ejemplo desde centros educativos que se abren al barrio o la comunidad (Flecha, Padrós \& Puig- 
dellívol, 2003); en iniciativas de trabajo integrado o comunitario que buscan resolver problemáticas específicas, por ejemplo la inclusión de adolescentes (Alsinet, Riba, Ribera \& Subirats, 2003; Santibáñez \& Martínez-Pampliega, 2013); en proyectos más globales como el movimiento de Ciudades Educadoras y la generación de los Proyectos Educativos de Ciudad (Blanco, 2006; Subirats, 2007); o en la articulación sistemática y estratégica de proyectos de acción socioeducativa a nivel local -en contextos determinadosa partir de la colaboración de los actores implicados en un mismo territorio organizados en Redes Socioeducativas a nivel local (Civís \& Longás, 2015). De entre estas últimas, algunas experiencias destacadas son: las Zones d'Action Prioritaire (Francia, 1982), las Education Action Zones (Reino Unido, 1998), las Extended Schools (Reino Unido, 2004), The Harlem Children's Zone (Estados Unidos, 1990) o los Planes de Entorno y las Redes Educativas Locales (España, 2000).

En este monográfico contamos con la aportación de investigadores que conocen directamente algunas de estas experiencias, más que propiamente de trabajo en red, de desarrollo de redes como formas de dar respuesta educativa a nivel local. Nuevos modos de coordinar y optimizar la intervención entre agentes e instituciones dependientes de diferentes administraciones y de la sociedad civil, que emergen como modos verdaderamente innovadores de atención efectiva a las necesidades socioeducativas de los ciudadanos (Díaz-Gibson, Civís \& Longás, 2013; Civís \& Longás, 2015), al impulso de la innovación social colaborativa (Sorensen \& Torfing, 2011) y a la construcción de capital social en las comunidades (Agranoff \& McGuirre, 2003). Concretamente se han seleccionado 4 artículos que aportan el estado actual del trabajo en red y las redes de colaboración a nivel internacional, con especial énfasis en el liderazgo y la gobernanza de estas experiencias, y 3 artículos centrados en diferentes momentos y funciones de la evaluación aplicada desde el programa CaixaProinfancia en la monitorización de redes locales para el desarrollo socioeducativo de la infancia vulnerable por causa de la pobreza (actualmente el programa socioeducativo de colaboración público-privada más relevante en España).

Entre todos los trabajos se abordan los aspectos más críticos de este tipo de iniciativas como son su liderazgo, las relaciones de las redes con la innovación social y el aprendizaje profesional, su puesta en marcha contextualizada a partir de la evaluación inicial; y la valoración de su impacto sobre la comunidad y las personas. Las lecturas se complementan entre sí para realizar un acercamiento global a estos enfoques emergentes de la intervención/ acción socioeducativa, poniendo de manifiesto su validez teórico-práctica a partir de distintas investigaciones evaluativas.

El primer artículo, a partir de una investigación en Estados Unidos, sitúa el foco sobre el liderazgo edu- cativo y la importancia de su ejercicio contextualizado, necesariamente vinculado al trabajo en red en la medida que crecen las relaciones y dependencias entre diferentes culturas y organizaciones. La puesta en marcha de cualquier proceso de esta índole requiere una aproximación global a las necesidades y los recursos, capaz de integrar una mirada transversal y sistémica desde el primer momento en el que se toma contacto con la comunidad y el territorio. En esta dirección, se muestra de modo aplicado un estudio sobre la infancia en situación de pobreza en Bilbao como paso previo a promover un trabajo en redes territoriales de colaboración público privada en la ciudad. A continuación (tercer artículo), desde una experiencia contrastada en un distrito escolar en California (Estados Unidos) que atiende a miles de estudiantes, se presentan aspectos claves de la gobernanza de las redes y se analizan los factores más decisivos para un liderazgo productivo y sostenible. El cuarto artículo aborda como el trabajo en red permite una mejor comprensión de las realidades de la infancia y sus familias, de modo que este conocimiento construido colaborativamente en sí mismo es generador de mejores acciones, eleva las expectativas de éxito e incide también en el desarrollo profesional de los actores implicados. Este aspecto, el cambio a nivel de culturas profesionales, es estudiado de modo muy específico en el quinto artículo a partir de una muestra de docentes holandeses. La investigación afirma que el sentido de eficacia profesional correlaciona positivamente con la calidad de las redes sociales de los docentes. La vinculación entre conectividad, las lógicas del trabajo en red y el fortalecimiento del capital social individual junto con la misma profesionalidad nos lleva a especular sobre la validez de las hipótesis que asocian las redes con el desarrollo profesional de los diferentes actores educativos y no sólo de los docentes. El sexto artículo presenta los efectos y la viabilidad del cambio que está experimentando el programa CaixaProinfancia en España, desde un modelo inicial de corte asistencialista a la actual propuesta basada en la acción territorial, contextualizada, sistémica y en red. Con ello se señalan caminos posibles para la evolución de las políticas públicas desde lo que nos atrevemos a formular como paradigma de la acción socioeducativa en escenarios de complejidad. Por último, el séptimo artículo realiza una revisión de las teorías que sustentan las redes de acción socioeducativa y de su contribución a la innovación social y educativa, argumentando el potencial del liderazgo en red para maximizar el impacto de todos los actores socioeducativos de un territorio. Un artículo, este último, que tanto podría tener valor de introducción al conjunto de las investigaciones presentadas como el valor casi conclusivo que por su posición en el monográfico le hemos otorgado. 
Sólo nos queda, para finalizar esta presentación, señalar que dada la complejidad de realidades y escenarios en los que está comprometida la educación, y ante cierta ineficiencia de las políticas tradicionales de bienestar, se impone abrir los ojos y las mentes a las formas de trabajo colaborativo que, venciendo dificultades, se abren paso progresivamente. Por parte de quienes impulsan el desarrollo de la comunidad en todos sus aspectos, reconocer la interdependencia de los problemas y las soluciones, así como promover la visión conjunta de los desafíos socioeducativos y del tipo de vida y/o escenarios deseables es la mejor manera de estimular la responsabilidad compartida y la colaboración. Pero esto es sólo el primer paso para romper con las respuestas en exceso fragmentadas por causa de la hiperespecialización disciplinar y con sus procesos de institucionalización altamente burocratizados. El territorio, la proximidad, la participación y la innovación se dan la mano como atributos de una mayor "inteligencia social", inteligencia que se construye en red como organizaciones cada vez más estudiadas y como metáfora de las redes neuronales que activa nuestro cerebro en su desarrollo de la inteligencia de cada individuo.

\section{Referencias bibliográficas}

Agranoff, R., \& McGuirre, M. (2003). Collaborative Public Management: new strategies for local governaments. Washington DC: Georgetown University Press.

Alsinet, J., Riba, C., Ribera, M., \& Subirats, J. (2003). Més enllà de l'escola. Transformacions socials i noves dinàmiques educatives i professionals. Barcelona: Mediterrània.

Blanco, I. (2006). Los proyectos educativos de la ciudad. Una experiencia de gobernanza local. Aula de innovación educativa, 152, 18-21.

Caride, J.A. (2004). No hay educación "no formal”. Educación Social. Revista de Intervención Socioeducativa, 338, $63-83$.

Castells, M. (2000). The Rise of the Network Society. The Information Age: Economy, Society and Culture (Vol. I). Malde, M.A: Blacwell.

Civís, M., \& Riera, J. (2007). La nueva pedagogía comunitaria. Un marco renovado para la acción sociopedagógica interprofesional. Valencia: Nau llibres.

Civís, M., \& Longás, J. (2015). La colaboración interinstitucional como respuesta al desafío de la inclusión socioeducativa. Análisis de 4 experiencias de trabajo en red a nivel local en Cataluña. Educación XX1, 18 (1), 213-236.

Díaz-Gibson, J., Civís, M., \& Longás, J. (2013). La gobernanza de redes socioeducativas: claves para una gestión exitosa. Teoría de la Educación, 25, 2-2013, 213-230.

Flecha, R., Padrós, M,. \& Puigdellívol, I. (2003). Comunidades de Aprendizaje: transformar la organización escolar al servicio de la comunidad. Organización y gestión educativa, 5, septiembre-octubre 2003, 4-8.

Fullan, M., \& Langworthy, M. (2013). Towards a New End: New Pedagogies for Deep Learning. Washington DC: Published by Collaborative Impact Seattle.

Longás, J. (2008). Redes socioeducativas locales y desarrollo comunitario. Introducción. Cultura y Educación, 20 (3), 263 265.

March, M., \& Orte, C. (2014). La pedagogia social y la escuela. Barcelona: Octaedro.

Ortega, J. (2005). La educación a lo largo de la vida: La educación social, la educación escolar, la educación continua... todas son educaciones formales. Revista de Educación, 338, 167-175.

Santibáñez, R., \& Martínez-Pampliega, A. (2013). Intervención comunitaria con adolescentes y familias en riesgo. Barcelona: Graó.

Sorensen, E., \& Torfing, J. (2011). Enhancing Collaborative Innovation in the Public Sector: An Analytical Framework. Administration \& Society, 43 (8), 842-868.

Subirats, M. (2007). Ciudades educadoras: un proyecto cargado de futuro. CEE Participación Educativa, 6, noviembre 2007, 51-59. 
